\title{
Comparison of methods to develop an emotional lexicon of wine: Conventional $v s$ rapid-method approach
}

\author{
María Mora, Amanda Dupas de Matos, Virginia Fernández-Ruiz, Teresa Briz, Carolina Chaya
}

\begin{abstract}
A B S T R A C T
The development of emotional lexicons can be seen as a time- and resource-consuming activity. Several rapid methods have been developed for time-restricted studies, but the suitability of these methodologies in the development of emotional lexicons compared to conventional ones has not been investigated.

The aim of this study was to test the suitability of a rapid method, as it is the Sorting Task, for emotional lexicon development compared to a conventional procedure. For this purpose, two different approaches (conventional $v s$ rapid-method) were tested to evaluate wines.

222 consumers participated in the lexicon development procedure. A common phase of generation and filtering of the terms was carried out for the development of both lexicons. Then, two approaches were used, one applying the procedures proposed in the literature (conventional, herein as Lexicon I) and the other applying Sorting Task (rapid-method, herein as Lexicon II). To test both lexicons, consumer studies $(n=185)$ were conducted using a set of seven commercial wines.

Both methods were helpful in discriminating emotional responses. Lexicon I reported a wine effect for 10 of the 13 emotional categories, while the Lexicon II discriminated the samples in all 15 categories. Although multifactorial analysis showed a high agreement between configurations $(\mathrm{RV}=0.985)$, the emotional map of both lexicons did not follow the theoretical circumplex model of emotions. SADNESS and NOSTALGIA feelings were related to the second axis.

In conclusion, both methods provided similar maps of wines, but Lexicon II was more efficient in terms of time and resources during the lexicon development.
\end{abstract}

\section{Introduction}

The study of the emotional response triggered by foods has gained attention in scientific literature because it is a useful tool to differentiate and to improve the product position in the marketplace (Cardello et al., 2016; Danner et al., 2016; Ferrarini et al., 2010; van Zyl, 2016). In recent years, many authors have developed emotional lexicons to measure the emotional response elicited by the consumption of different food products (e.g., Danner et al., 2016; Gmuer, Nuessli Guth, Runte, \& Siegrist, 2015; Hu \& Lee, 2019; Mora, Giussani, Pagliarini, \& Chaya, 2019; Silva et al., 2016). Some models proposed that emotions are mainly driven by two dimensions related to valence (pleasure/displeasure) and activation/arousal (low/high), which is the general scheme of the circumplex model (Larsen \& Diener, 1992; Russel, 1980; Watson \& Tellegen, 1985). More recently, a 12-point emotion circumplex structure was proposed to measure the core affect, integrating the feelings resulting from moods and emotions (Yik, Russell, \& Steiger, 2011).

Although there is a wide variety of emotional lexicons in the literature, several authors have showed a better description of emotional responses when a specific lexicon for the product category is applied (Ng, Chaya, \& Hort, 2013; Silva et al., 2016). To choose the correct method to measure emotions triggered by foods, some issues should be considered: 1) the potential of the method to capture differences, 2) the culture, and 3) the length of the questionnaire. The ability to detect differences among products will be conditioned by the specificity of the 
lexicon. Even though generic emotional lexicons (King \& Meiselman, 2010; Spinelli, Masi, Dinnella, Zoboli, \& Monteleone, 2014; Thomson \& Crocker, 2013) could be used to measure the emotional response of any food category, the development of specific lexicons could be more suitable to capture more subtle different feelings or emotions among samples within a certain product category (Ng et al., 2013; Silva et al., 2016; van Zyl, 2016). Culture might affect the use, the dimension, the meaning of emotional terms, and also the consumers' familiarity to the product (van Zyl \& Meiselman, 2015, 2016). Emotional lexicons might only be used by consumers for the culture which they are designed, because emotion words and their meanings can influence the emotional connection that consumers have with the product (van Zyl, 2016; van Zyl \& Meiselman, 2015). The length of the questionnaire will affect the time/effort required by the consumer to complete the task of reporting the emotions elicited by a product (Cardello et al., 2016; van Zyl, 2016). Some authors have used different procedures or methodologies to reduce the length and the difficulty of the task. For example, Chaya et al. (2015) applied Hierarchical Cluster Analysis (HCA) to group terms with similar ratings into emotional categories, and to reduce the length of the questionnaire. The effectiveness of this approach was analyzed by Eaton, Chaya, Smart, and Hort (2019). Considering all these factors, when the emotional response elicited by food is assessed, specific "shorter/easier" questionnaires or methods belonging to the consumers' culture must be applied.

It is important to consider that the development of emotional lexicons is a time- and resource-consuming activity. The "conventional" method to generate emotional lexicons is conducted after four different steps: 1) terms generation, 2) reduction of terms by removing synonyms and irrelevant terms, 3) grouping of terms into categories to reduce the length of the questionnaire (optional step), and 4) testing of the lexicon. For the first step (terms generation), three principal approaches have been reported in the literature, depending on the source of the emotional terms: a) consumer-led approaches, where consumers generate the emotional terms (Bhumiratana, Adhikari, \& Chambers, 2014; Chaya et al., 2015; Ng et al., 2013; Silva et al., 2016), b) linguistic-based approaches, where specialists or researchers present an existing list of emotions from the literature (Ferrarini et al., 2010; Gmuer et al., 2015; King \& Meiselman, 2010), and c) a combination of the two previous methods, where consumers generate the emotional terms with the support of terms from the bibliography (Danner et al., 2016; Manzocco, Rumignani, \& Lagazio, 2013; van Zyl \& Meiselman, 2015). Once the terms have been generated, the synonyms should be removed from the list, and a panel of consumers has to check the relevance of the emotional words for the studied product. Then, in some cases, additional consumer tests are carried out to rate the emotions elicited by several products with different sensory properties using the emotional terms previously developed. Hierarchical Cluster Analysis is used to group the different emotions into emotional categories; this step may need to be supervised by the research team (Chaya et al., 2015; Eaton et al., 2019; Mora et al., 2019). Finally, the resulting lexicon has to be tested to confirm its ability to measure the emotional response evoked by the specific product. Therefore, the current procedure defined in the literature is time-consuming and expensive, because of the many steps included in the process and the need to recruit a large number of consumers and samples to draw conclusions.

Rapid methods are methodologies that have gained popularity in recent years being reliable options when quick information is needed. The application of these methods can provide a quick output about consumers' perception and preferences (Varela \& Ares, 2014). Sorting Task is a methodology designed to collect the global degree of similarity among samples; in this method, assessors or consumers classify different stimuli together based on their perceived similarities (Chollet, Valentin, \& Abdi, 2014). This methodology is a holistic procedure based on the cognitive process of categorization in which a routine process used in everyday life does not need a quantitative response. In the sensory field, sorting task was firstly introduced by Lawless (1989) as a method for mapping aromas. From that moment on, this methodology has widely been used in different sensory studies of product characterization (e.g.: Parr, Green, White, \& Sherlock, 2007; Thomsen, Gourrat, Thomas-Danguin, \& Guichard, 2014). Considering that Sorting Task is a useful tool for grouping samples regarding their similarities and differences, it could be applied to generate an emotional lexicon, shortening the length of the procedure or classifying emotions (Nestrud, Meiselman, King, Lesher, \& Cardello, 2016; Thomson \& Crocker, 2013). Also, it could be applied to group feelings into emotional categories reducing the number of steps and the time and resources invested in a lexicon development procedure.

Therefore, the aim of the present research was to test the suitability of a rapid-method, like Sorting Task, for emotional lexicon development, specifically wine emotional lexicons, compared to the conventional procedure. For this purpose, two different approaches, conventional (time- and resource- consuming) $v s$ rapid-method, were applied to wine matrices and compared.

\section{Material and methods}

\subsection{Samples}

In order to have as much sensory variation as possible, seven different commercial wines of different wine styles (red, rosé, white, sparkling white, sparkling rosé, sweet and semi-sweet wines) were selected for this study. Descriptive sensory analysis was conducted by a trained panel as described in Mora, Urdaneta, and Chaya (2018). ANOVA followed by a Post hoc test Tukey HSD was carried out to ensure diversity of the sensory properties for all the wines. Details of the samples used in the study are reported in Table 1 . Rosé, white and sparkling wines were served at $8{ }^{\circ} \mathrm{C}( \pm 0.2)$ and red wines were served at $16{ }^{\circ} \mathrm{C}( \pm 0.2)$, following the winery recommendations. Samples were placed into transparent closed screw cap universal containers in all the steps.

\subsection{Consumer-led lexicon development}

A total of 222 Spanish consumers participated in the whole procedure of lexicon development. The consumers panel was balanced according to age and gender. To take part in the study participants had to consume wine at least once a month.

The initial steps related to the generation, filtering, and reduction of terms were common for both lexicons $(n=161)$. Then, different steps were followed to develop both emotional lexicons (lexicons I and II). The procedures are described in Fig. 1.

\subsubsection{Procedure for generating terms}

Nine focus groups were employed to generate the emotions related to wine consumption of both lexicons. 99 Spanish participants (aged from 20 to 75 years old), who consumed wine at least once a month were split in nine focus groups (11 participants each) to take part in this part of the study. The consumers panel was balanced according to age and gender.

The focus group session protocol was divided into three parts following the procedure of Chaya et al. (2015). In the first part, a short explanation of the objective of the focus group was presented. The participants were then instructed about the differences between emotions and moods following the description used by King and Meiselman (2010): emotions are brief, intense, and focused on a referent (e.g., The comment made me angry), and moods are more enduring, build up gradually, are more diffuse, and not focused on a referent (e.g., I am happy). During the second part, to stimulate emotion elicitation, a warm up exercise was conducted using different pictures and prompt cards (Ng et al., 2013). Participants were indicated to look at each picture and individually answer the question "how do you feel after looking at this picture?" Once all the consumers were ready, a 
Table 1

P-values and mean scores of the sensory descriptors of wine samples.

\begin{tabular}{|c|c|c|c|c|c|c|c|c|}
\hline \multirow[t]{2}{*}{ Sensory attributes } & 1 & 2 & 3 & 4 & 5 & 6 & 7 & \multirow[t]{2}{*}{ p-value } \\
\hline & $\begin{array}{l}\text { Red wine } \\
\text { (2012) }\end{array}$ & $\begin{array}{l}\text { Sparkling rosé wine } \\
(2017)\end{array}$ & $\begin{array}{l}\text { Rosé wine } \\
\text { (2017) }\end{array}$ & $\begin{array}{l}\text { Sparkling white wine } \\
(2017)\end{array}$ & $\begin{array}{l}\text { Red wine } \\
(2014)\end{array}$ & $\begin{array}{l}\text { Semi-sweet white } \\
\text { wine (2017) }\end{array}$ & $\begin{array}{l}\text { Red wine } \\
(2017)\end{array}$ & \\
\hline Flowers & $0.906 \mathrm{c}$ & $2.719 \mathrm{bc}$ & $2.356 \mathrm{bc}$ & $3.800 \mathrm{ab}$ & $0.381 \mathrm{c}$ & $5.438 \mathrm{a}$ & $1.983 \mathrm{bc}$ & $<0.0001$ \\
\hline Violet & $1.719 \mathrm{a}$ & $1.275 \mathrm{a}$ & $1.944 \mathrm{a}$ & $0.931 \mathrm{a}$ & $0.912 \mathrm{a}$ & $1.044 \mathrm{a}$ & $2.375 \mathrm{a}$ & 0.1402 \\
\hline Clove & $1.563 \mathrm{ab}$ & $0.156 \mathrm{~b}$ & $0.769 \mathrm{ab}$ & $0.381 \mathrm{~b}$ & $1.406 \mathrm{ab}$ & $0.244 \mathrm{~b}$ & $2.096 \mathrm{a}$ & 0.0002 \\
\hline Pepper & $1.163 \mathrm{ab}$ & $0.169 \mathrm{~b}$ & $0.275 \mathrm{~b}$ & $0.200 \mathrm{~b}$ & $2.319 \mathrm{a}$ & $0.138 \mathrm{~b}$ & $2.179 \mathrm{a}$ & $<0.0001$ \\
\hline Licorice & $0.631 \mathrm{a}$ & $0.550 \mathrm{a}$ & $0.575 \mathrm{a}$ & $0.844 \mathrm{a}$ & $0.256 \mathrm{a}$ & $0.675 \mathrm{a}$ & $0.821 \mathrm{a}$ & 0.8315 \\
\hline Lemon & $0.150 \mathrm{a}$ & $0.475 \mathrm{a}$ & $0.425 \mathrm{a}$ & $1.331 \mathrm{a}$ & $0.119 \mathrm{a}$ & $1.113 \mathrm{a}$ & $0.550 \mathrm{a}$ & 0.0377 \\
\hline Blackberry & $2.569 \mathrm{a}$ & $1.150 \mathrm{abc}$ & $0.450 \mathrm{bc}$ & $0.281 \mathrm{c}$ & $2.019 \mathrm{ab}$ & $0.169 \mathrm{c}$ & $0.800 \mathrm{bc}$ & $<0.0001$ \\
\hline Raspberry & $1.800 \mathrm{a}$ & $1.338 \mathrm{a}$ & $1.694 \mathrm{a}$ & $0.187 \mathrm{a}$ & $1.944 \mathrm{a}$ & $0.406 \mathrm{a}$ & $1.829 \mathrm{a}$ & 0.0238 \\
\hline Strawberry & $1.200 \mathrm{ab}$ & $1.638 \mathrm{ab}$ & $2.256 \mathrm{a}$ & $0.425 \mathrm{~b}$ & $0.969 \mathrm{ab}$ & $0.681 \mathrm{ab}$ & $2.092 \mathrm{a}$ & 0.0049 \\
\hline Blueberry & $1.981 \mathrm{a}$ & $0.956 \mathrm{a}$ & $1.144 \mathrm{a}$ & $0.300 \mathrm{a}$ & $1.463 \mathrm{a}$ & $0.275 \mathrm{a}$ & $1.642 \mathrm{a}$ & 0.1217 \\
\hline Peach & $0.163 \mathrm{a}$ & $0.888 \mathrm{a}$ & $0.869 \mathrm{a}$ & $1.256 \mathrm{a}$ & $0.212 \mathrm{a}$ & $1.063 \mathrm{a}$ & $0.654 \mathrm{a}$ & 0.1617 \\
\hline Apple & $0.150 \mathrm{c}$ & $0.487 \mathrm{bc}$ & $0.731 \mathrm{bc}$ & $2.275 \mathrm{a}$ & $0.106 \mathrm{c}$ & $1.794 \mathrm{ab}$ & $0.742 \mathrm{bc}$ & $<0.0001$ \\
\hline Pineapple & $0.081 \mathrm{c}$ & $0.631 \mathrm{bc}$ & $0.494 \mathrm{c}$ & $2.844 \mathrm{a}$ & $0.119 \mathrm{c}$ & $2.119 \mathrm{ab}$ & $0.512 \mathrm{c}$ & $<0.0001$ \\
\hline Banana & $0.475 \mathrm{a}$ & $1.088 \mathrm{a}$ & $0.425 \mathrm{a}$ & $1.263 \mathrm{a}$ & $0.106 \mathrm{a}$ & $1.050 \mathrm{a}$ & $0.742 \mathrm{a}$ & 0.2239 \\
\hline Tea & $0.563 \mathrm{a}$ & $0.263 \mathrm{a}$ & $0.219 \mathrm{a}$ & $0.100 \mathrm{a}$ & $0.438 \mathrm{a}$ & $0.113 \mathrm{a}$ & $0.608 \mathrm{a}$ & 0.2105 \\
\hline Nut & $0.600 \mathrm{a}$ & $0.119 \mathrm{a}$ & $0.625 \mathrm{a}$ & $0.425 \mathrm{a}$ & $0.425 \mathrm{a}$ & $0.144 \mathrm{a}$ & $0.663 \mathrm{a}$ & 0.6015 \\
\hline Vanilla & $1.706 \mathrm{a}$ & $1.138 \mathrm{a}$ & $0.950 \mathrm{a}$ & $1.363 \mathrm{a}$ & $1.150 \mathrm{a}$ & $1.100 \mathrm{a}$ & $2.179 \mathrm{a}$ & 0.4149 \\
\hline Coffee & $0.344 \mathrm{a}$ & $0.888 \mathrm{a}$ & $0.244 \mathrm{a}$ & $0.100 \mathrm{a}$ & $0.994 \mathrm{a}$ & $0.100 \mathrm{a}$ & $0.338 \mathrm{a}$ & 0.0663 \\
\hline Butter & $0.988 \mathrm{a}$ & $0.506 \mathrm{a}$ & $0.319 \mathrm{a}$ & $0.738 \mathrm{a}$ & $0.181 \mathrm{a}$ & $0.388 \mathrm{a}$ & $0.417 \mathrm{a}$ & 0.3828 \\
\hline Mushroom & $0.613 \mathrm{ab}$ & $0.150 \mathrm{~b}$ & $0.219 \mathrm{ab}$ & $0.100 \mathrm{~b}$ & $0.994 \mathrm{a}$ & $0.313 \mathrm{ab}$ & $0.325 \mathrm{ab}$ & 0.0209 \\
\hline Acidity & $4.794 \mathrm{a}$ & $1.194 \mathrm{c}$ & $4.438 \mathrm{a}$ & $4.519 \mathrm{a}$ & $3.513 \mathrm{ab}$ & $1.756 \mathrm{bc}$ & $5.483 \mathrm{a}$ & $<0.0001$ \\
\hline Sweetness & $0.706 \mathrm{~b}$ & $4.994 \mathrm{a}$ & $1.513 \mathrm{~b}$ & $1.638 \mathrm{~b}$ & $0.575 \mathrm{~b}$ & $5.494 \mathrm{a}$ & $1.279 \mathrm{~b}$ & $<0.0001$ \\
\hline Astringency & $4.681 \mathrm{a}$ & $0.750 \mathrm{~b}$ & $1.750 \mathrm{~b}$ & $1.844 \mathrm{~b}$ & $5.813 \mathrm{a}$ & $1.281 \mathrm{~b}$ & $4.275 \mathrm{a}$ & $<0.0001$ \\
\hline Carbonation & $0.956 \mathrm{~b}$ & $2.475 \mathrm{ab}$ & $0.906 \mathrm{~b}$ & $4.675 \mathrm{a}$ & $1.125 \mathrm{~b}$ & $1.088 \mathrm{~b}$ & $0.421 \mathrm{~b}$ & $<0.0001$ \\
\hline
\end{tabular}

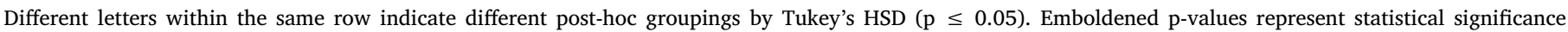
( $\mathrm{p} \leq 0.05)$.

discussion took place to collect all the elicited emotions. During the third part of the focus groups, consumers repeated the same process as the second part, but using different wines instead of pictures/cards.

Each consumer received triad of samples $(10 \mathrm{~mL}$ each) from the seven wines (Table 1) following Incomplete Block Design. Then, the participants were instructed to taste the wines and describe how they felt when drinking each sample in a written questionnaire. According to previous research (Chaya et al., 2015; Ng et al., 2013), consumers were introduced to triadic elicitation to help terms generation: they were asked to assess triads of wine samples describing what make two samples similar but different from the third one in terms of emotional response elicited. To avoid carry-over effects, consumers were asked to take a minimum of one-minute break between wines. In addition, each participant received unsalted crackers and mineral water as palate cleansers. Later, emotions and feelings were discussed and collected in an initial list of terms, being the kick off for the lexicon development.

\subsubsection{Filtering and reduction of terms}

The initial list of the emotional terms was checked and verified to remove synonyms and terms which were not considered emotions. The list was checked following the method of van Zyl and Meiselman (2015) in which each term was compared with the emotional lists published by Clore, Ortony, and Foss (1987) and Laros and Steenkamp (2005) containing 564 and 50 terms, respectively. The terms generated in the focus group sessions that were not included in any of the two published lists were removed.

To reduce the number of emotional terms included in the filtered list, two different procedures to determine their relevance were also conducted using other 62 Spanish consumers: a relevance test (RT) and a grouping of irrelevant terms (GIT). To do so, two consumer panels were recruited. All of them had to consume wine at least once a week. For the RT, 30 consumers were asked to rate each emotional term according to the question: "In your opinion, are the following terms relevant in describing how do you feel when consuming wine?". A $10 \mathrm{~cm}$ linear scale, anchored from "absolutely irrelevant" to "absolutely relevant", was used for the rating. Terms with a mean 'relevance' score $<33 \%$ were considered as not relevant and were excluded from the lexicon. For the GIT, 32 consumers received the list of emotions and were asked to remove all the terms that they considered irrelevant when consuming wine. The terms which were rejected by $\geq 30 \%$ of the consumers were removed from the lexicon list. The percentage of elimination of terms was performed according to Chaya et al. (2015), Gmuer et al. (2015) and (Mora et al., 2019).

\subsubsection{Grouping of terms into emotion categories}

The previous stage filtered and reduced the initial list. Two different approaches were subsequently used to group the terms into emotional categories. Both approaches are explained below.

2.2.3.1. Conventional approach. Using the approach of Chaya et al. (2015), the seven wines (Table 1) were evaluated by another panel of 33 Spanish consumers. Participants tasted each wine sample (25 mL) and rated each evoked emotional term from the list obtained after the filtering and reduction task. A warm-up sample was used to minimize the first position effect (Dorado, Pérez-Hugalde, Picard, \& Chaya, 2016). Wines were served in random order according to a Complete Balanced Block design. Rating was conducted using a 10-cm continuous line scale anchored from 'very low' to 'very high' using Compusense ${ }^{\circledast}$ Cloud software (Compusense Inc., Guelph, Ontario, Canada). To minimize bias, the emotions were presented in a randomized order for each consumer. Three sessions were necessary to develop the conventional approach.

A Hierarchical Cluster Analysis (HCA) was conducted with the average ratings of each emotional term to group similar emotions into categories. Terms were grouped using Euclidean distance and the Ward's criterion of aggregation. Once emotions were grouped into categories by HCA, three different researchers supervised the emotion groups individually. After that, a consensus was reached on the final groups and categories' names. Additionally, to confirm the categories' names of the groups, the feedback from an external expert (psychologist) from the University of the Basque Country (UPV/EHU) was considered. Subsequently, internal consistency of each category was 


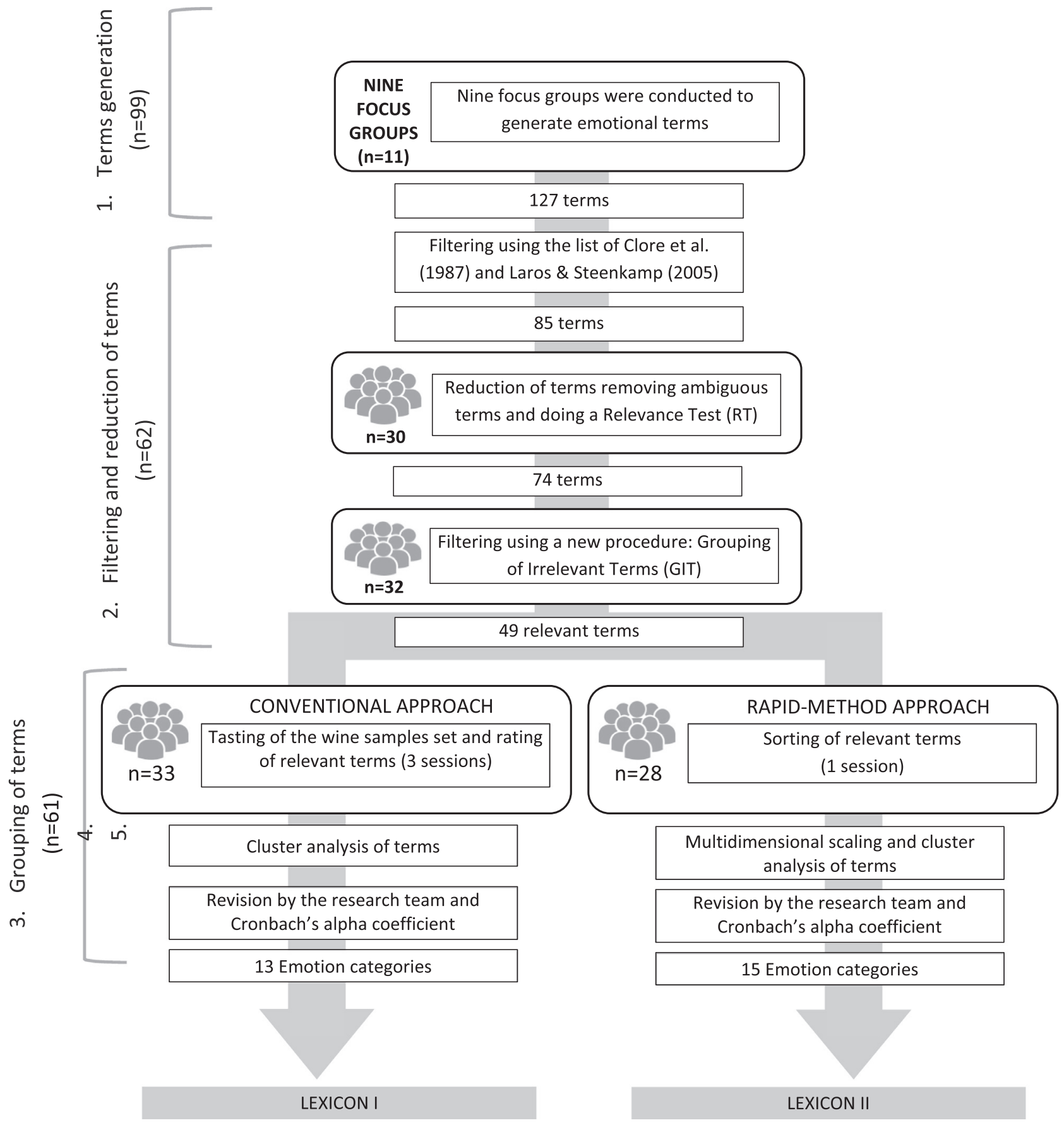

Fig. 1. Flow chart of the lexicon development by both Conventional and Rapid-method approaches.

verified by the Cronbach's alpha coefficient.

All statistical analyses were done using XLSTAT (XLSTAT Version 2018.7, USA) (Addinsoft, 2019).

2.2.3.2. Rapid-method approach. To study the possibility of simplifying the development of an emotional lexicon, Sorting Task (Chollet et al., 2014) was explored as a method to cluster feelings into emotional categories with a semantic approach using another panel of 28 wine Spanish consumers. Each consumer was asked to group the emotions or feelings from the filtered and reduced list using the criteria of joining emotions with similar meaning for them. For this purpose, consumers were asked to think in a wine consumption context.

Participants were free to propose as many groups as they considered necessary. The rapid-method approach was carried out in only one session. The distances between emotions obtained from consumer classifications were analyzed by Multidimensional Scaling (MDS). The MDS treated data from a proximity matrix between a series of $\mathrm{N}$ objects to the coordinates of the same objects in a p-dimensional space through the use the algorithm "Scaling by Majorizing a Convex Function", which minimizes the Normalized Stress. To determine the correct number of dimensions needed to obtain a true representation of data, stress should be low, and the Shepard diagram should be as linear as possible (Addinsoft, 2019).

Once the dimensions' configuration was determined, HCA was performed on the projection of emotion terms to group similar emotions into categories. Emotions were grouped using Euclidean distance and the Ward's criterion of aggregation. In the same manner as in the conventional procedure, emotion categories supervision and their 
names were first done individually by triangulation. Once the consensus was reached, the categories' names were confirmed by the psychologist assessment again. Also, the Cronbach's alpha coefficient was used to ensure that the resulting categories had internal consistency.

All statistical analyses were done using XLSTAT (XLSTAT Version 2018.7, USA) (Addinsoft, 2019).

\subsection{Testing of lexicons}

\subsubsection{Consumers}

185 Spanish consumers (51\% males, mean age of 51 years old), different from those involved in the development procedure, participated in the testing procedure. The consumers' panel was randomly split into two groups to test lexicon I (conventional approach) or lexicon II (rapid-method approach).

\subsubsection{Testing procedure}

Seven wine samples $(25 \mathrm{~mL})$ were presented to the consumers (Table 1) in random order using a Complete Balanced Block design. After tasting each wine, the consumers were first asked to rate the overall liking on a 9-point scale. Then, they had to read all the terms associated to each emotion category and rate the intensity of the evoked feelings by each wine evaluated by a 10-cm linear scale, anchored from 'very low' to 'very high'. They were instructed to focus on their feelings associated to each specific wine sample and not to their general mood. Data collection was done using Compusense ${ }^{\circledast}$ Cloud software (Compusense Inc., Guelph, Ontario, Canada). To minimize bias, the order of the emotion categories was randomized for each consumer. Also, a warmup sample was introduced into the experimental design (Dorado et al., 2016; Wakeling \& MacFie, 1995) to avoid the first position effect.

\subsubsection{Data analysis}

ANOVA followed by a Post hoc test (Tukey HSD) was carried out on liking and each emotional category. Significant differences were determined with a significance level of 0.05 unless stated otherwise.

Principal Component Analysis (PCA) was performed on the average ratings of each emotional category to explore the relationships between emotional categories and wines. Liking was used as a supplementary (non-active) variable in the analysis.

HCA was carried out using the averages of each emotional category per wine. The cluster analysis was based on the Euclidean distance, and the Ward algorithm was used as the agglomerative method.

To determine the relationship among the emotional categories, the wines, and the two lexicons, a Multiple Factor Analysis (MFA) was conducted with the mean ratings of each emotion category. Again, liking was used as a supplementary variable. The RV coefficient was also calculated to compare the emotional maps of wines obtained with both lexicons.

All statistical analyses were done using XLSTAT (XLSTAT Version 2018.7, USA) (Addinsoft, 2019).

\section{Results}

\subsection{Consumer-led lexicon development}

The lexicon development was a complex process composed of many steps. Fig. 1 shows a flow chart of the process and reports the evolution of the number of terms at each stage of the development of the lexicons.

\subsubsection{Common steps of the consumer-led lexicon: generation, filtering and reduction of terms}

During the first step of the lexicon generation, the focus groups generated a total of 127 emotional terms (Table 2). These 127 terms were compared and filtered with the emotional lists reported by Clore et al. (1987) and Laros and Steenkamp (2005). After the filtering, the initial list was reduced from 127 to 85 terms (Table 2). Then, two analyses were conducted to ensure that the remaining terms were relevant to the study of the emotional response elicited by wine consumption: i) RT and ii) GIT. The relevance test caused a reduction of 11 terms, and the grouping of irrelevant terms reduced the list by 25 additional emotions. The results of these steps provided a final list of 49 emotions and feelings related to the wine consumption experience (Table 2).

\subsubsection{Grouping of terms: Conventional approach}

The HCA analysis grouped the emotions into 15 emotional categories. The triangulation by three researchers improved the final emotion categories by slightly modifying the clusters (reducing the categories). Also, the research team, using the information collected from the focus groups and HCA analysis, decided the names of the emotional categories. To decide the category name, one feeling of the emotional category was selected. Then, the final name categories were supervised by a psychologist. It is important to note that modifications were done in the original language of the terms (Spanish). Terms and translation are presented in Table 2. For example, the cluster composed of "Displeasured" and "Weird" had a very low Cronbach's alpha. Based on the similarities with other groups, these terms were joined with the cluster CONFUSED, obtaining a final Cronbach's alpha cluster value of 0.926. Similarly, the cluster composed of "Pleased", "Quiet", "Relaxed" and "Refreshed" were included in the CALM cluster, obtaining a final Cronbach's alpha value of 0.909. Finally, the cluster DISPLEASED, initially composed of "Disgusted", "Displeased", "Strong" and "Sleepy" was modified moving the last two terms into other categories. "Strong" was included in the category EUPHORIC, and "Sleepy" was added to the INDIFFERENCE cluster. Both groups increased their Cronbach's alpha value after including the aforementioned items. After these modifications, the final lexicon I resulted in 13 emotional categories (Table 3).

\subsubsection{Grouping of terms: Rapid-method approach}

Using the sorting proximity matrix, different 16-dimensional representation spaces were calculated by MDS. A final number of 16 dimensions was chosen because the stress value of the 16 dimensions (0.043) was the weakest, and the Shepard diagram was the most linear compared to other dimensions number (Fig. 2). Projection of emotions on the 16-dimension configuration was input in HCA resulting in 14 clusters of emotions. The internal consistency of each dimension was calculated, and the dimensions with lowest Cronbach's alpha values were adjusted. At this stage, and similarly to the conventional approach, triangulation by three different researchers was required to improve the categorization and naming the emotional categories. Resulting name categories were supervised by a psychologist at the end. The cluster composed of the emotions "Curious", "Strong", and "Refreshed" was modified splitting the group into three. "Refreshed" and "Curious" represented two single categories, and "Strong" was included in the FUN category. Finally, lexicon II had 15 emotional categories (Table 3). The resulting categories presented a good internal consistency measured by Cronbach's alpha values.

\subsection{Testing of lexicons}

Once the lexicons were defined, their ability for wine discrimination was assessed.

\subsubsection{Lexicon $I$}

ANOVA tests showed that 11 of the 13 categories of lexicon I (YEARNING, WARM, CONFUSED, GLAD, DESIROUS, DISPLEASED, EXCITED, EUPHORIC, HAPPY, INDIFFERENCE, and SAFE) were significantly different among samples. Post hoc analyses identified different wine groups for each emotional category (Table 4).

The first two Principal Components of the Principal Component Analysis (PCA) explained $92.68 \%$ of the data variance (Fig. 3a). PC1 was positively correlated with CALM (0.928), WARM (0.988), GLAD 
Table 2

Terms generated in the common process before clustering (terms translated into English are in italics).

\begin{tabular}{|c|c|c|c|c|c|}
\hline English & Spanish & English & Spanish & English & Spanish \\
\hline Overwhelmed & Abrumado** & Difficult & Difícil* & Obligation & Obligación* \\
\hline Bored & Aburrido**** & Displeased & Disgustado & Leisured & Ocioso* \\
\hline Accelerated & Acelerado* & Fun & Divertido & Hate & Odio** \\
\hline Welcome & Acogido $^{* * *}$ & Gentle & Dulzura** & Lazy & Pereza*** \\
\hline Wonder & Admirado*** & Excited & Emocionado-entusiasmado & Heavy & Pesado* \\
\hline Affectionate & Afectuoso & Energetic & Enérgico & Pleasure & Placer \\
\hline Lucky & Afortunado & Jealous & Envidioso** & Fullness & Plenitud* \\
\hline Burdened & Agobiado*** & Hopeful & Esperanzado*** & Positive & Positivo* \\
\hline Nice & Agradable* & Spiritual & Espiritual* & Powerful & Potente $e^{* * *}$ \\
\hline Grateful & Agradecido $* * *$ & Stable & Estable* & Worried & Preocupado** \\
\hline Cheerful & Alegre & Euphoric & Eufórico & Beloved & Querido*** \\
\hline Bitter & Amargado*** & Excited & Excitado & Rage & Rabioso** \\
\hline Friendly & Amigable & Expectation & Expectación*** & Rancid & Rancio* \\
\hline Loving & Amoroso & Estrange & Extrañado* & Weird & Raro \\
\hline Distressed & Angustiado** & Familiar & Familiar* & Rejection & Rechazo* \\
\hline Joyful & Animado & Annoyed & Fastidiado*** & Comforting & Reconfortante* \\
\hline Anxious & Ansioso-deseoso & Hарру & Feliz & Refreshed & Refrescado \\
\hline Yearning & Añoranza & Playful & Fiestero & Relaxed & Relajado \\
\hline Distressed & Apenado*** & Cool & Fresco* & Repulsion & Repulsión* \\
\hline Disgusted & Asqueado & Frustrated & Frustrado*** & Sentimental & Romántico \\
\hline Attraction & Atracción** & Strong & Fuerte & Rustic & Rustico* \\
\hline Aversion & Aversión $* * *$ & Weariness & Hastío* & Satisfied & Satisfecho \\
\hline Good & Bien & Homelike & Hogareño* & Saturated & Saturado* \\
\hline Warm & Cálido & Excited & Ilusionado & Safe & Seguro \\
\hline Calm & Calmado & Doubt & Incertidumbre ${ }^{* * *}$ & Sensitive & Sensible \\
\hline Tired & Cansado*** & Uncomfortable & Incomodo* & Serenity & Sereno \\
\hline Warm & Cariñoso & Indifference & Indiferencia & Serious & Serio*** \\
\hline Closeness & Cercanía* & Unexpected & Inesperado* & Sociable & Sociable* \\
\hline Sparkler & Chisposo* & Restless & Inquieto $* * *$ & Alone & Soledad $* * *$ \\
\hline Pleased & Complacido & Unsatisfied & Insatisfecho* & Sleepy & Somnoliento/Adormilado \\
\hline Common & Común* & Intense & Intenso* & Negatively surprised & Sorprendido negativamente \\
\hline Comfortable & Confortado & Uneasy & Intranquilo $* *$ & Positively surprised & Sorprendido positivamente \\
\hline Confused & Confuso & Humorous & Jocoso* & Relaxed & Sosegado*** \\
\hline Glad & Contento & Young & Joven* & Fear & Temor** \\
\hline Curious & Curiosidad & Free & Libertad* & Tense & Tenso*** \\
\hline Corny & Cursi* & Light & Ligero* & Tender & Tierno*** \\
\hline Disappointment & Decepcionado & Wrong & $\mathrm{Mal}^{*}$ & Quiet & Tranquilo \\
\hline Displeasured & Desagradado & Melancholy & Melancólico & Sadness & Tristeza \\
\hline Discouraged & Desanimado*** & Monotonous & Monótono* & Summer & Veraniego* \\
\hline Discontent & Descontento & Motivated & Motivado* & Old & Viejo* \\
\hline Desirous & Deseo* & Negative & Negativo* & Vulnerable & Vulnerable ${ }^{* *}$ \\
\hline Disinterested & Desinterés* & Nervous & Nervioso ${ }^{* * *}$ & & \\
\hline Carefree & Despreocupado & Nostalgic & Nostálgico & & \\
\hline
\end{tabular}

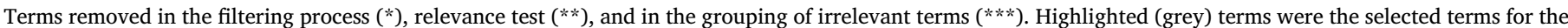
subsequent analysis, after filtering and reduction steps.

(0.976), DESIROUS (0.985), EXCITED (0.986), EUPHORIC (0.960), and HAPPY (0.992) categories, whereas categories CONFUSED (-0.838), DISPLEASED (-0.867), and INDIFFERENCE (-0.881) were negatively correlated. PC2 was positively correlated with the SADNESS $(0.818)$ category.

Fig. $3 \mathrm{~b}$ was helpful for the interpretation of the grouping of wines by HCA. Wines 6 and 2 (grouped together) were related positively with the PC1 and elicited higher ratings on positive emotions than wines 7 and 3 (grouped in another cluster). Wines 7 and 3 were negatively related to PC1 and showed higher ratings on negative emotions than wines 6 and 2 . These groupings are supported by the Tukey test results (Table 2), in which a statistically significant grouping of wines 2 and 6 versus 3 and 7 are found in the categories WARM, GLAD, DESIROUS, EXCITED, EUPHORIC, and HAPPY. Yet, the groups of wines 1 and 5, and wine 4, were positively and negatively related to PC2, respectively. Wines 1 and 5 elicited higher ratings of feelings related to SADNESS category than wine 4. However, these differences were not significant (Table 4) and PC2 represented only $14.62 \%$ of the total variance. Therefore, the interpretation of the influence of SADNESS category in the general grouping of wines should be considered as less relevant.

\subsubsection{Lexicon II}

ANOVA test showed that all emotional categories of lexicon II were significantly different among wines. Post hoc analyses identified different wine groupings for each emotional category (Table 4).

The first two Principal Components of the PCA explained $96.03 \%$ of the data variance (Fig. 4a). The horizontal axis was positively correlated with AFFECTIONATE (0.984), LUCKY (0.960), JOYFUL (0.990), CHEERFUL (0.983), CURIOUS (0.976), DESIROUS (0.967), FUN (0.982), RELAXED (0.951), SATISFIED (0.922), and SENSITIVE (0.980). It was negatively correlated with SLEEPY (-0.910), DISPLEASED (-0.954), and SADNESS (-0.949). The vertical axis was positively correlated with the emotional category NOSTALGIC (0.965).

The HCA of wines resulting from lexicon II, provided a similar configuration to the one obtained from lexicon I (Fig. 4b). Wines 6 and 2 (one group) were positively related with PC1, whereas wines 7 and 3 (another group) were negatively related with this axis. According to the relationship among wines and emotions, wines 6 and 2 had higher ratings on positive emotions compared to wines 7 and 3, which had higher ratings on negative emotions than wines 6 and 2. These results are supported by Tukey test (Table 4). Wines 7 and 3 belong to statistically significant groups from wines 6 and 2 on emotion categories AFFECTIONATE, LUCKY, JOYFUL, CHEERFUL, DESIROUS, DISPLEASED, FUN, REFRESHED, and SATISFIED. Likewise, wines 1 and 5 (one group) were positively associated to PC2, whereas wine 4 was negatively associated with this axis. This result suggests that wines 1 and 5 
Table 3

Lexicon I and II categories.

\begin{tabular}{|c|c|c|c|c|c|}
\hline \multicolumn{3}{|l|}{ LEXICON I } & \multicolumn{3}{|l|}{ LEXICON II } \\
\hline Categories & Terms & $\begin{array}{l}\text { Cronbach's } \\
\text { alpha }\end{array}$ & Categories & Terms & $\begin{array}{l}\text { Cronbach's } \\
\text { alpha }\end{array}$ \\
\hline YEARNING Añoranza & Cálido/Añoranza/Melancólico & 0.815 & SLEEPY Adormilado & Adormilado & - \\
\hline $\begin{array}{l}\text { CALM } \\
\qquad \text { Calma }\end{array}$ & $\begin{array}{l}\text { Sensible/Calmado/Sereno/ } \\
\text { Complacido/Tranquilo/Relajado/ } \\
\text { Refrescado }\end{array}$ & 0.909 & $\begin{array}{l}\text { AFFECTIONATE } \\
\text { Afectuoso }\end{array}$ & $\begin{array}{l}\text { Afectuoso/Amoroso/Cálido/Cariñoso/ } \\
\text { Romántico }\end{array}$ & 0.943 \\
\hline $\begin{array}{l}\text { WARM } \\
\text { Cariñoso }\end{array}$ & $\begin{array}{l}\text { Romántico/Cariñoso/Satisfecho/Bien/ } \\
\text { Amoroso }\end{array}$ & 0.948 & LUCKY Afortunado & Afortunado/Agradecido/Confortado & 0.923 \\
\hline CONFUSED Confuso & $\begin{array}{l}\text { Sorprendido negativamente/Confuso/ } \\
\text { Descontento/Desagradado/Raro }\end{array}$ & 0.926 & $\begin{array}{l}\text { JOYFUL } \\
\text { Alegre }\end{array}$ & Alegre/Contento/Feliz/Ilusionado & 0.962 \\
\hline $\begin{array}{l}\text { GLAD } \\
\qquad \text { Contento }\end{array}$ & $\begin{array}{l}\text { Contento/Divertido/Fiestero/ } \\
\text { Ilusionado/Amigable }\end{array}$ & 0.955 & CHEERFUL Animado & Amigable/Animado/Bien & 0.935 \\
\hline DESIROUS Deseoso & Ansioso- deseoso & - & CURIOUS Curiosidad & Curiosidad & - \\
\hline DISPLEASED Disgustado & Asqueado/Disgustado & 0.862 & DESIROUS Deseoso & $\begin{array}{l}\text { Ansioso- deseoso/Emocionado- } \\
\text { entusiasmado/Excitado/Placer/ } \\
\text { Sorprendido positivamente }\end{array}$ & 0.914 \\
\hline EXCITED Entusiasmado & $\begin{array}{l}\text { Emocionado-entusiasmado/Alegre/ } \\
\text { Curiosidad }\end{array}$ & 0.919 & $\begin{array}{l}\text { DISPLEASED } \\
\text { Disgustado }\end{array}$ & $\begin{array}{l}\text { Asqueado/Confuso/Desagradado/ } \\
\text { Descontento/Disgustado/Indiferencia/ } \\
\text { raro/Sorprendido negativamente }\end{array}$ & 0.938 \\
\hline EUPHORIC Eufórico & $\begin{array}{l}\text { Animado/Eufórico/Enérgico/Excitado/ } \\
\text { Fuerte }\end{array}$ & 0.863 & $\begin{array}{l}\text { FUN } \\
\text { Divertido }\end{array}$ & $\begin{array}{l}\text { Divertido/Enérgico/Eufórico/Fiestero/ } \\
\text { Fuerte }\end{array}$ & 0.862 \\
\hline $\begin{array}{l}\text { HAPPY } \\
\text { Feliz }\end{array}$ & $\begin{array}{l}\text { Feliz/Sorprendido positivamente/ } \\
\text { Afectuoso/Afortunado/Feliz/ } \\
\text { Agradecido/Placer/Confortado/ }\end{array}$ & 0.965 & NOSTALGIC Nostálgico & Añoranza/Melancólico/Nostálgico & 0.886 \\
\hline $\begin{array}{l}\text { INDIFFERENCE } \\
\text { Indiferencia }\end{array}$ & Indiferencia/Adormilado & 0.602 & REFRESHED Refrescado & Refrescado & - \\
\hline $\begin{array}{l}\text { SAFE } \\
\text { Seguro }\end{array}$ & Despreocupado/Seguro & 0.589 & RELAXED Relajado & $\begin{array}{l}\text { Calmado/Despreocupado/Relajado/ } \\
\text { Sereno/Tranquilo }\end{array}$ & 0.872 \\
\hline SADNESS Tristeza & Nostálgico/Tristeza & 0.495 & $\begin{array}{l}\text { SATISFIED Satisfecho } \\
\text { SENSITIVE Sensible }\end{array}$ & $\begin{array}{l}\text { Complacido/Satisfecho/Seguro } \\
\text { Sensible }\end{array}$ & $\begin{array}{l}0.876 \\
-\end{array}$ \\
\hline & & & $\begin{array}{l}\text { SADNESS } \\
\text { Tristeza }\end{array}$ & Tristeza & - \\
\hline
\end{tabular}

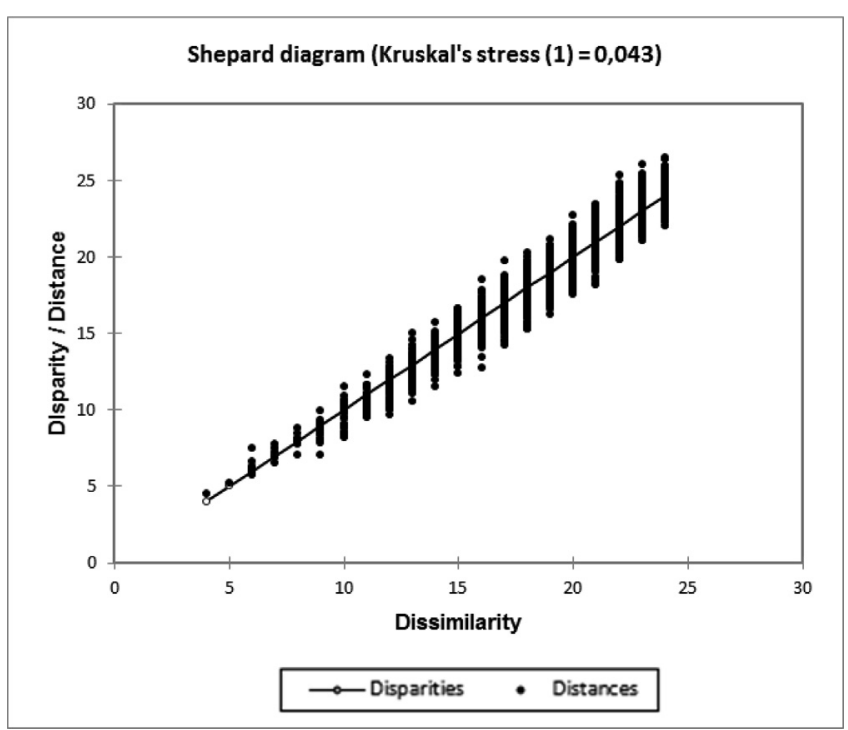

Fig. 2. Shepard diagram resulting from the MDS analysis of the semantic lexicon.

were more related to the NOSTALGIC emotional category compared to wine 4. But the only significant difference of NOSTALGIC category was found between wines 5 and 3 (Table 4) according to Tukey test. Moreover, the relevance of PC2 (10.61\% of the total variance) mitigates the effect of NOSTALGIC category on the explanation of the whole differences among wine groupings.

\subsection{Comparison of lexicons}

Comparing the univariate analysis results from lexicons I and II, both lexicons were suitable in discriminating wine emotional responses. Lexicon I had a wine effect for 10 of the 13 emotional categories, while lexicon II discriminated wines in all 15 categories.

To study the relationship between the emotional maps of both lexicons, MFA was conducted resulting in a very similar configuration of the wines, with a RV coefficient of 0.985 . This result was reinforced by the observation plots of lexicons I and II (Figs. $3 \mathrm{~b}$ and $4 \mathrm{~b}$, respectively) where the samples were plotted similarly, and also by the HCA results. The major differences between both lexicons were found in PC2: in lexicon I, PC2 was mainly driven by SADNESS, and in lexicon II by NOSTALGIC. However, in both cases PC2 accounted for a small variance of the data $(14.62 \%$ and $10.61 \%$, respectively) and wine groupings from HCA were not confirmed on the univariate analysis of those categories.

\section{Discussion}

The main objective of the present study was to evaluate if the Sorting Task methodology was a suitable procedure to develop a consumer-led emotional lexicon of wine compared to a conventional procedure. Results showed that the application of Sorting Task could be useful in the lexicon development procedure for emotions, reducing steps and resulting in a less time-consuming approach. Also, it was proven that both approaches were similar in discriminating emotional responses elicited by different types of wines.

RT and GIT were suitable procedures for removing irrelevant emotions or feelings from the list of terms obtained from the focus 
Table 4

P-values and mean scores for the two lexicons' emotional categories and liking across the seven wines.

\begin{tabular}{|c|c|c|c|c|c|c|c|c|c|}
\hline & Categories & p-value & 1 & 2 & 3 & 4 & 5 & 6 & 7 \\
\hline \multirow{14}{*}{ LEXICON I } & Liking & $<0.0001$ & $5.107 \mathrm{~b}$ & $6.123 \mathrm{a}$ & $4.539 \mathrm{~b}$ & $5.391 \mathrm{ab}$ & $5.009 \mathrm{~b}$ & $6.096 \mathrm{a}$ & $4.704 \mathrm{~b}$ \\
\hline & YEARNING & 0.0009 & $3.279 \mathrm{abc}$ & $3.742 \mathrm{ab}$ & $2.369 \mathrm{c}$ & $2.633 \mathrm{bc}$ & $3.807 \mathrm{a}$ & $3.406 \mathrm{abc}$ & $3.113 \mathrm{abc}$ \\
\hline & CALM & 0.1636 & $4.079 \mathrm{a}$ & $4.497 \mathrm{a}$ & $3.431 \mathrm{a}$ & 3.959 a & $4.014 \mathrm{a}$ & $4.147 \mathrm{a}$ & $3.540 \mathrm{a}$ \\
\hline & WARM & $<0.0001$ & $3.409 \mathrm{~b}$ & $4.852 \mathrm{a}$ & $2.999 \mathrm{~b}$ & $3.626 \mathrm{ab}$ & $3.776 \mathrm{ab}$ & $4.668 \mathrm{a}$ & $3.040 \mathrm{~b}$ \\
\hline & CONFUSED & 0.0270 & $3.513 \mathrm{a}$ & $2.289 \mathrm{~b}$ & $3.175 \mathrm{ab}$ & $2.859 \mathrm{ab}$ & $2.964 \mathrm{ab}$ & $2.317 \mathrm{ab}$ & $3.083 \mathrm{ab}$ \\
\hline & GLAD & $<0.0001$ & $4.059 \mathrm{abc}$ & $5.233 \mathrm{a}$ & $3.149 \mathrm{c}$ & $4.387 \mathrm{abc}$ & $3.831 \mathrm{bc}$ & $4.981 \mathrm{ab}$ & $3.517 \mathrm{c}$ \\
\hline & DESIROUS & 0.0001 & $3.643 \mathrm{ab}$ & $4.665 \mathrm{a}$ & $3.019 \mathrm{~b}$ & $3.844 \mathrm{ab}$ & $3.523 \mathrm{ab}$ & 4.517 a & $3.026 \mathrm{~b}$ \\
\hline & DISPLEASED & 0.0013 & $3.192 \mathrm{a}$ & $1.767 \mathrm{~b}$ & $2.981 \mathrm{a}$ & $2.506 \mathrm{ab}$ & $2.973 \mathrm{a}$ & $2.020 \mathrm{ab}$ & $2.885 \mathrm{ab}$ \\
\hline & EXCITED & $<0.0001$ & $3.889 \mathrm{ab}$ & $4.866 \mathrm{a}$ & $3.141 \mathrm{~b}$ & $3.972 \mathrm{ab}$ & $3.890 \mathrm{ab}$ & $4.947 \mathrm{a}$ & $3.457 \mathrm{~b}$ \\
\hline & EUPHORIC & 0.0007 & $3.945 \mathrm{ab}$ & $4.595 \mathrm{a}$ & $3.030 \mathrm{~b}$ & $4.027 \mathrm{ab}$ & $3.700 \mathrm{ab}$ & $4.402 \mathrm{a}$ & $3.133 \mathrm{~b}$ \\
\hline & HAPPY & $<0.0001$ & $3.842 \mathrm{~b}$ & $5.304 \mathrm{a}$ & $3.136 \mathrm{~b}$ & $4.135 \mathrm{ab}$ & $3.921 \mathrm{~b}$ & $5.188 \mathrm{a}$ & $3.437 \mathrm{~b}$ \\
\hline & INDIFFERENCE & 0.0010 & $2.942 \mathrm{ab}$ & $2.247 \mathrm{~b}$ & $3.808 \mathrm{a}$ & $3.187 \mathrm{ab}$ & $2.570 \mathrm{~b}$ & $2.679 \mathrm{~b}$ & $3.355 \mathrm{ab}$ \\
\hline & SAFE & 0.0392 & $4.563 \mathrm{a}$ & $4.398 \mathrm{a}$ & $3.636 \mathrm{a}$ & $4.204 \mathrm{a}$ & $4.421 \mathrm{a}$ & $4.734 \mathrm{a}$ & $3.550 \mathrm{a}$ \\
\hline & SADNESS & 0.1307 & $3.006 \mathrm{a}$ & $2.060 \mathrm{a}$ & $2.341 \mathrm{a}$ & $2.242 \mathrm{a}$ & $2.620 \mathrm{a}$ & $2.330 \mathrm{a}$ & $2.683 \mathrm{a}$ \\
\hline \multirow[t]{16}{*}{ LEXICON II } & Liking & $<0.0001$ & $5.522 \mathrm{ab}$ & $6.046 \mathrm{a}$ & $4.004 \mathrm{~d}$ & $5.442 \mathrm{ab}$ & $4.912 \mathrm{bc}$ & $6.209 \mathrm{a}$ & $4.553 \mathrm{~cd}$ \\
\hline & SLEEPY & 0.0192 & $2.755 \mathrm{ab}$ & $2.024 \mathrm{~b}$ & $2.705 \mathrm{ab}$ & $2.533 \mathrm{ab}$ & $2.943 \mathrm{ab}$ & $2.233 \mathrm{ab}$ & $3.081 \mathrm{a}$ \\
\hline & AFFECTIONATE & $<0.0001$ & $4.042 \mathrm{bc}$ & $5.406 \mathrm{a}$ & $3.066 \mathrm{c}$ & $3.988 \mathrm{bc}$ & $3.570 \mathrm{c}$ & $5.148 \mathrm{ab}$ & $3.290 \mathrm{c}$ \\
\hline & LUCKY & $<0.0001$ & $4.075 \mathrm{ab}$ & $4.828 \mathrm{a}$ & $2.874 \mathrm{c}$ & $3.970 \mathrm{abc}$ & $3.801 \mathrm{abc}$ & $4.799 \mathrm{a}$ & $3.228 \mathrm{bc}$ \\
\hline & JOYFUL & $<0.0001$ & $4.231 \mathrm{bcd}$ & $5.531 \mathrm{a}$ & $3.314 \mathrm{~d}$ & $4.706 \mathrm{abc}$ & $3.761 \mathrm{~cd}$ & $5.001 \mathrm{ab}$ & $3.326 \mathrm{~d}$ \\
\hline & CHEERFUL & $<0.0001$ & $4.473 \mathrm{ab}$ & $5.406 \mathrm{a}$ & $3.271 \mathrm{c}$ & $4.719 \mathrm{ab}$ & $3.827 \mathrm{bc}$ & $5.170 \mathrm{a}$ & $3.624 \mathrm{bc}$ \\
\hline & CURIOUS & $<0.0001$ & $3.995 \mathrm{abc}$ & $5.140 \mathrm{a}$ & $3.154 \mathrm{c}$ & $4.007 \mathrm{abc}$ & $3.518 \mathrm{c}$ & $4.712 \mathrm{ab}$ & $3.587 \mathrm{bc}$ \\
\hline & DESIROUS & $<0.0001$ & $3.944 \mathrm{abc}$ & $4.918 \mathrm{a}$ & $2.776 \mathrm{~d}$ & $4.146 \mathrm{ab}$ & $3.702 \mathrm{bcd}$ & $4.412 \mathrm{ab}$ & $2.992 \mathrm{~cd}$ \\
\hline & DISPLEASED & 0.0002 & $2.676 \mathrm{abc}$ & $2.043 \mathrm{bc}$ & $3.143 \mathrm{a}$ & $2.620 \mathrm{abc}$ & $3.137 \mathrm{ab}$ & $1.855 \mathrm{c}$ & $3.278 \mathrm{a}$ \\
\hline & FUN & $<0.0001$ & $3.843 \mathrm{bc}$ & $5.128 \mathrm{a}$ & $3.121 \mathrm{c}$ & $4.445 \mathrm{ab}$ & $3.662 \mathrm{bc}$ & $4.627 \mathrm{ab}$ & $3.059 \mathrm{c}$ \\
\hline & NOSTALGIC & 0.0415 & $3.375 \mathrm{ab}$ & $2.948 \mathrm{ab}$ & $2.560 \mathrm{~b}$ & $3.110 \mathrm{ab}$ & 3.729 a & $3.115 \mathrm{ab}$ & $3.557 \mathrm{ab}$ \\
\hline & REFRESHED & $<0.0001$ & $2.795 \mathrm{~b}$ & $5.326 \mathrm{a}$ & $3.225 \mathrm{~b}$ & $4.836 \mathrm{a}$ & $2.624 \mathrm{~b}$ & $4.660 \mathrm{a}$ & $2.843 \mathrm{~b}$ \\
\hline & RELAXED & $<0.0001$ & $4.025 \mathrm{bc}$ & $5.145 \mathrm{a}$ & $3.252 \mathrm{c}$ & $4.090 \mathrm{abc}$ & $4.121 \mathrm{abc}$ & $4.837 \mathrm{ab}$ & $3.764 \mathrm{bc}$ \\
\hline & SATISFIED & $<0.0001$ & $4.587 \mathrm{ab}$ & $5.346 \mathrm{a}$ & $2.938 \mathrm{c}$ & $4.219 \mathrm{ab}$ & $4.296 \mathrm{ab}$ & $5.234 \mathrm{a}$ & $3.551 \mathrm{bc}$ \\
\hline & SENSITIVE & $<0.0001$ & $3.425 \mathrm{bc}$ & $4.497 \mathrm{a}$ & $2.902 \mathrm{c}$ & $3.765 \mathrm{abc}$ & $3.516 \mathrm{abc}$ & $4.217 \mathrm{ab}$ & $3.210 \mathrm{bc}$ \\
\hline & SADNESS & 0.0005 & $2.594 \mathrm{a}$ & $1.607 \mathrm{~b}$ & $2.771 \mathrm{a}$ & $1.982 \mathrm{ab}$ & $2.676 \mathrm{a}$ & $1.935 \mathrm{ab}$ & $2.636 \mathrm{a}$ \\
\hline
\end{tabular}

Different letters within the same row indicate different post-hoc groupings by Tukey's HSD (p $\leq 0.05)$.

Emboldened p-values represent statistical significance $(\mathrm{p} \leq 0.05)$.

groups. Ferrarini et al. (2010) used a 5-point scale to remove irrelevant terms where 1 meant "the adjective is not at all suitable for describing the emotional experience of the wine" and 5 "the adjective is very suitable for describing the emotional experience of the wine". Similarly, Chaya et al. (2015) used a linear scale to rate the relevance of terms to measure the emotional response to beer. However, Bhumiratana et al. (2014) and Gunaratne et al. (2019) applied Check-All-That-Apply (CATA) methodology to eliminate unrelated emotions. Our study shows that GIT is a suitable method to remove irrelevant terms. Future studies might introduce GIT as part of the Sorting Task to reduce the length of the lexicon development. Authors recommend requiring the consumers to group irrelevant terms for the measurement of the emotional response of the product category at the beginning of the Sorting Task.

Sorting Task was applied in the present study as a method to group emotions and reduce the questionnaire length. Lexicon II, which was developed after grouping the emotions using the Sorting Task approach, had 15 emotional categories, whereas lexicon I, which was developed after grouping the emotions by sensory consumer tests, resulted in 13 emotional categories. Both lexicons had an acceptable length to ease the task for the consumers. Other authors have considered the length of emotional questionnaires as an important factor during the development of emotional lexicons and have proposed some procedures to shorten them. Ferrarini et al. (2010) introduced a final step to reduce the list from 23 into 16 emotional terms, when developing a lexicon to measure the emotional response elicited by wines with Italian consumers. Silva et al. (2018) proposed an initial step, before measuring the temporal dominance of emotions elicited by wine, to select the 10 main terms from a previous list generated in a qualitative study (Silva et al., 2016). Danner et al. (2016) proposed a final phase in the development of the Australian Wine Evoked Emotions Lexicon (AWEEL) to reduce the 16 emotional categories collected during the focus group sessions, into 16 representative emotions of each emotional category.

The present study showed that Sorting Task (Chollet et al., 2014) could reduce the time invested in lexicon development, using a semantic approach to cluster emotions and feelings into categories. While the conventional approach required three sessions plus the time invested in the preparation of the samples to be tasted by the consumers, the rapid-method approach only needed one session to be carried out and did not involve sensory exposure to the samples. In this sense, other authors have proposed different methods to reduce the effort when developing consumer-led emotional lexicons. For example, Chaya et al. (2015) proposed using focus groups as an alternative to the personal interviews used in Ng et al. (2013) and Spinelli et al. (2014) to reduce time during lexicon development. Also, Gunaratne et al. (2019) proposed conducting online surveys as a fast-screening method to develop simplified emotional lexicons.

Results from the present study found a sample effect for 10 of the 13 emotional categories in lexicon I, while lexicon II discriminated the wines in all 15 categories. In addition, the same wine groups and projections were found in the observation plots of both lexicons, with a high RV coefficient between maps. Although other metrics could be used to investigate associations between both configurations (Josse \& Holmes, 2016), the RV coefficient and the follow-up analysis, including the graphical output, proved that both methods provided similar output. And both of them, conventional (wine tasting) and rapidmethod (evoked wine tasting), were fairly appropriate in discriminating wine emotional responses.

According to the emotions' disposition in the first factorial plot of the PCA, the horizontal axis (PC1) was associated to valence (pleasure/ displeasure) emotions in both lexicons. Similar results were reported by Mora et al. (2018) and were consistent with the first dimension of the circumplex model of emotions (Larsen \& Diener, 1992; Russel, 1980; Watson \& Tellegen, 1985). However, the second dimension of the present study (PC2) did not follow the theoretical model of previous literature and reported in other studies, in which a clearer relationship between PC2 and activation/arousal was evidenced for wine (Mora 
a)

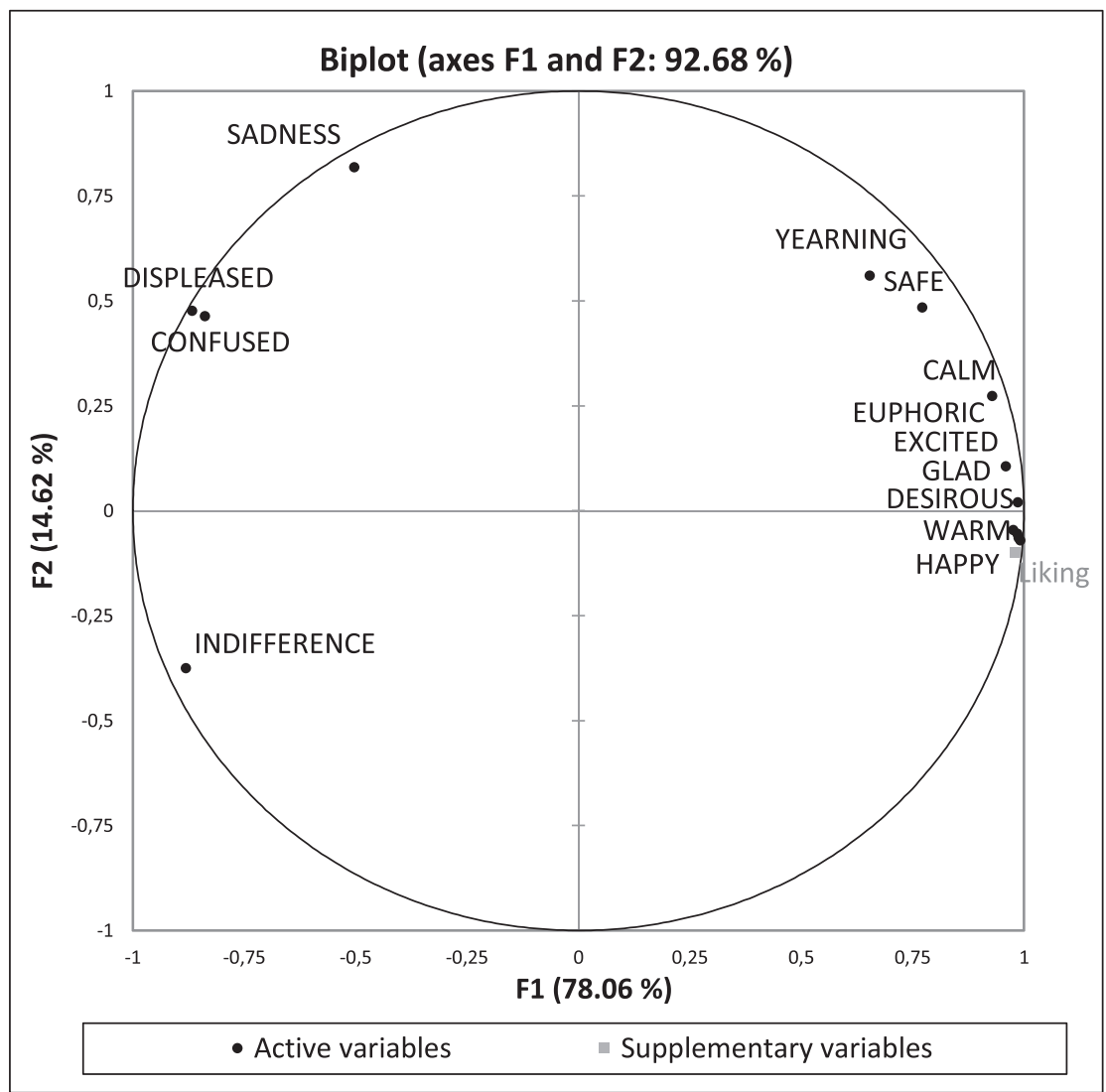

b)

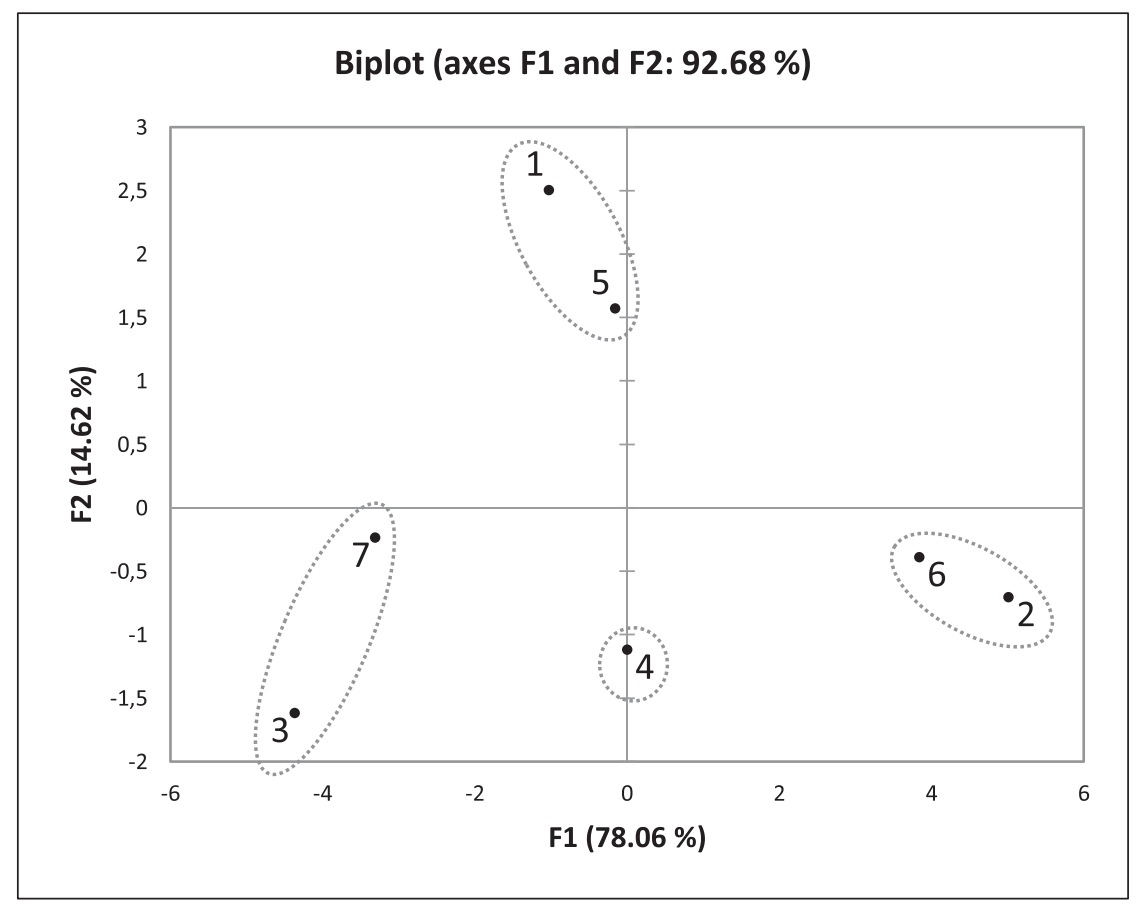

Fig. 3. First factorial plot of the PCA based on the emotional response to wines from lexicon I. (a) Correlation plot of emotions (b) Projection of wines. Groupings are based on clustering results of the same data set. 
a)

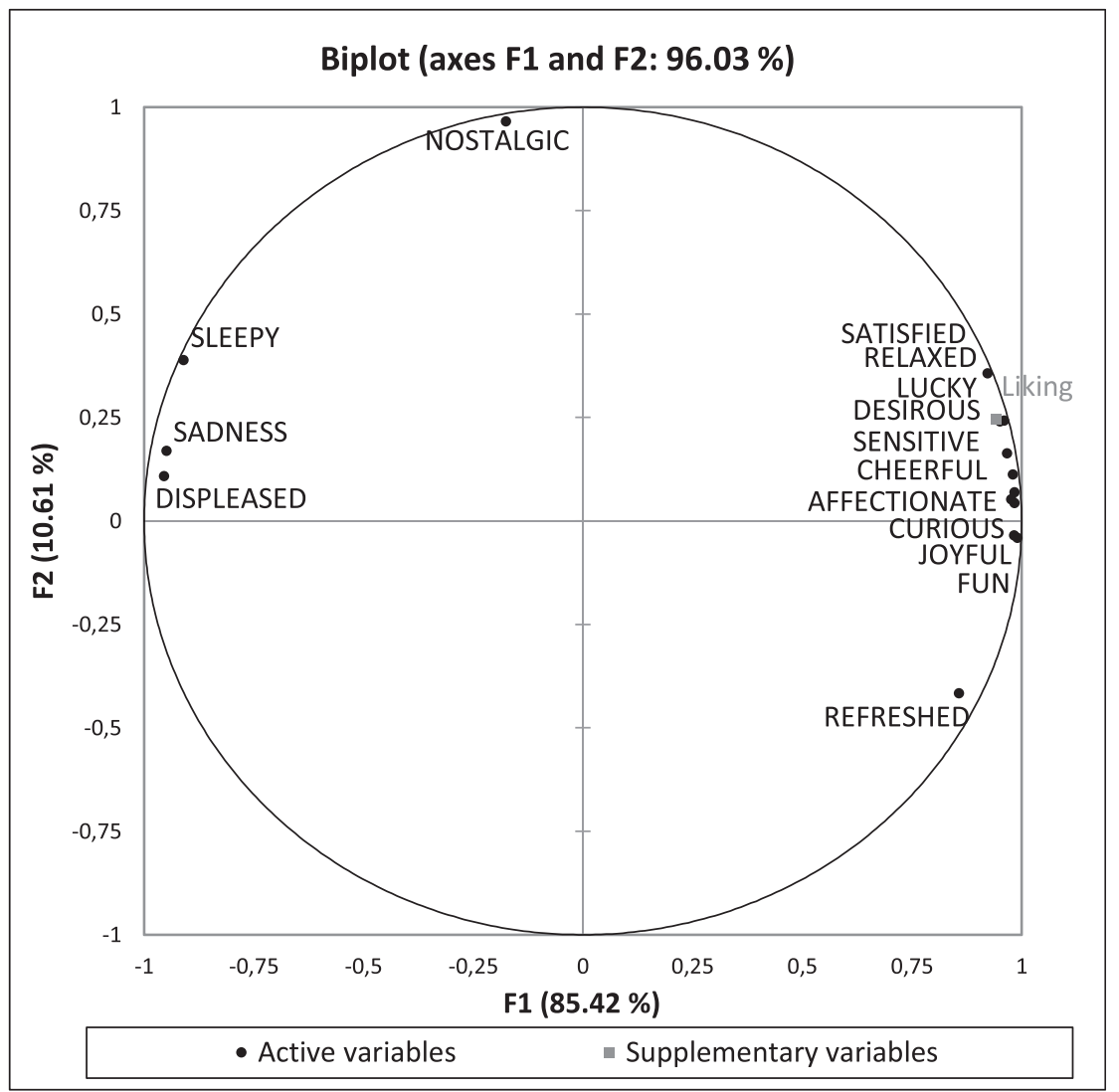

b)

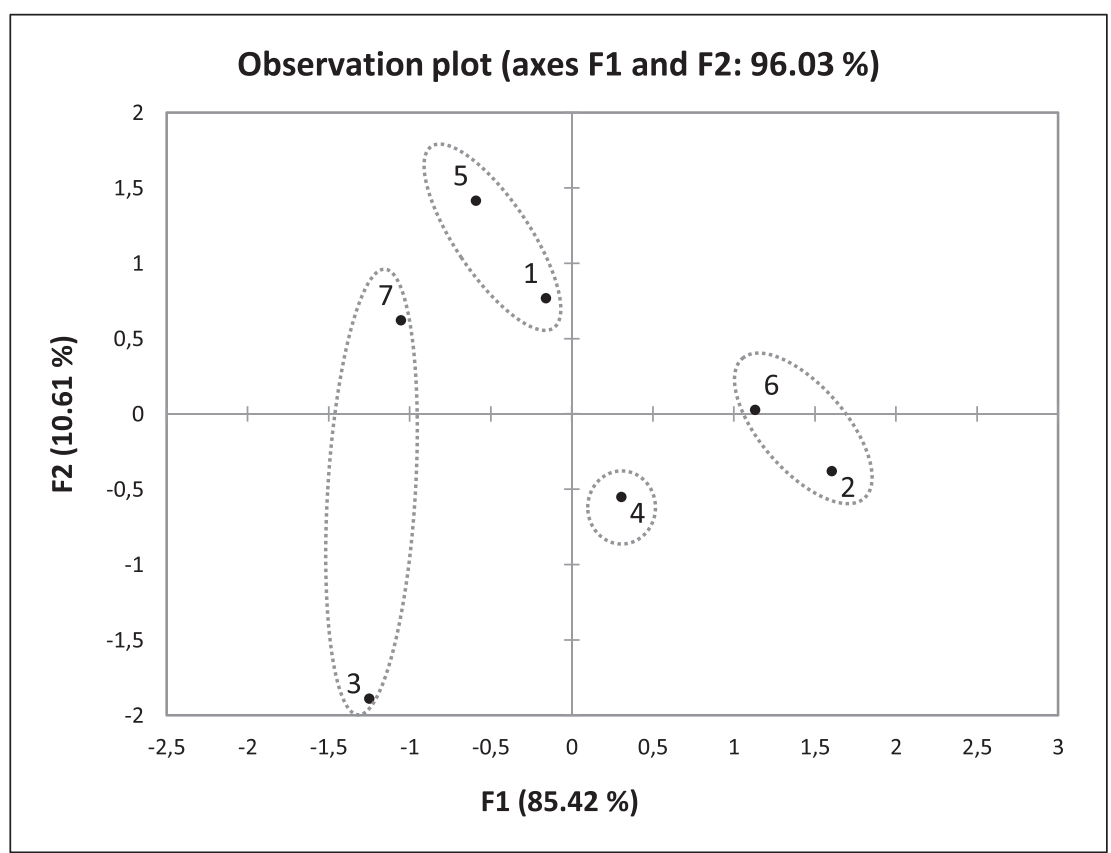

Fig. 4. First factorial plot of the PCA based on the emotional response to wines from lexicon II. (a) Correlation plot of emotions (b) Projection of wines. Groupings are based on clustering results of the same data set.

et al., 2018), blackcurrant squashes (Ng et al., 2013), beer (Chaya et al., 2015; Eaton et al., 2019, Mora et al., 2019), and coffee (Bhumiratana et al., 2014). Apparently, results from this research showed that the emotions associated with low or high activation were not so related to
PC2 but were more combined with the valence axis (PC1). Indeed, the fit to the circumplex model was not clear even in previous studies about wine and emotions. Ferrarini et al. (2010) reported that the first component (F1) included adjectives that described emotions which are 
characterized by intense pleasure and high-level arousal, the second component (F2) described pleasure and low to medium level arousal emotions, and finally, the third component (F3) included adjectives describing unpleasant emotions. Other authors identified four dimensions (evaluation-pleasantness, potency-control, activation-arousal, and unpredictability) to describe similarities and differences of emotion words (Fontaine, Scherer, Roesch, \& Ellsworth, 2007). Therefore, it seems that depending on the emotional words used to measure feelings elicited by products, the number and/or nature of dimensions to describe the feelings would vary to offer the most appropriate representation of the emotional response.

In the present study, the second axis was related to SADNESS in Lexicon I, and to NOSTALGIA in Lexicon II, showing that the activation/arousal dimension of the circumplex model was not suitable to describe the emotional configuration of our data. In the study of Ferrarini et al. (2010), the term sadness was not included at the final stage of the lexicon development, and the term nostalgia was discarded during the reduction stage. Moreover, nostalgia was not elicited by Dutch and Portuguese consumers in the more than one hundred list of terms associated to the consumption of wine or beer (Silva et al., 2016). Yet, Silva et al. (2016) found that the emotional conceptualization of wine with sad feelings was weak for Dutch consumers whereas it was not found to be associated for Portuguese consumers. However, our findings show that nostalgia and sadness could be relevant feelings to describe differences on emotional response associated to wines at least for Spanish consumers. Moreover, the idea that nostalgia and some low activated emotions are relevant terms to describe wine consumers' emotional response differences was previously reported by Danner et al. (2016), in which the feeling nostalgic was affected by wine quality for Australian consumers.

Differently, previous work (Mora et al., 2018) showed a good fit to the circumplex model for Spanish consumers of wine using a general lexicon (EsSense25). The authors did not find a significant effect of wine on nostalgia, but the PCA results showed that nostalgic was placed on both unpleasant and activated nature of the 2-dimensional map of emotions. To sum up, further studies are needed to investigate if the fit to the second axis of the circumplex model could be dependent on the product category, on the consumers' cultural origin, on the lexicon used to assess consumers' emotional response or on a combination of these factors.

\section{Conclusions}

The main conclusion of the present study is that the use of rapid methodologies such as Sorting Task was suitable for the development of a consumer-led wine emotional lexicon. This methodology was faster and fewer resources were consumed, having the same discrimination capacity as a lexicon developed using the procedure mainly proposed in the literature. The application of this rapid method could be useful in the development of emotional lexicons with a semantic approach, saving time and resources, without compromising the discrimination ability of the lexicon.

Although a first dimension associated to valence combined with activation was found, the second dimension was associated to SADNESS (for Lexicon I) and NOSTALGIA (for Lexicon II). According to our results, the latter feeling categories are relevant to describe differences on emotional response evoked by wines. This is an additional value of consumer-led lexicons as compared to general lexicons used previously to investigate emotional responses elicited by wine. Results suggest that the suitability of the 2-dimensional model could be dependent on the product category, on the consumers' cultural origin, and/or on the lexicon used to assess consumers' emotional response, but further studies are necessary on this research field.

The use of specific lexicons could provide additional insights to the relevant emotional categories for a given product and a specific cultural origin of consumers. To conclude, the current research provides a more efficient use of the resources during consumer-led lexicon development; however further research is required to validate the rapid-method approach (Lexicon II) using new sets of wines including a wider sensory variation. In addition, future studies could apply the proposed methodology to generate emotional lexicons considering other products and cultures.

\section{CRediT authorship contribution statement}

María Mora: Conceptualization, Methodology, Investigation, Formal analysis, Resources, Writing - original draft, Visualization, Writing - review \& editing. Amanda Dupas de Matos: Investigation, Resources, Writing - original draft, Writing - review \& editing. Virginia Fernández-Ruiz: Investigation, Resources. Teresa Briz: Investigation, Resources. Carolina Chaya: Conceptualization, Methodology, Investigation, Formal analysis, Resources, Writing - original draft, Writing - review \& editing, Supervision, Project administration, Funding acquisition.

\section{Acknowledgements}

This study was funded by project AGL2016-78936-R from the Spanish Ministry of Economy and Competitiveness (MINECO).

\section{Appendix A. Supplementary data}

Supplementary data to this article can be found online at https:// doi.org/10.1016/j.foodqual.2020.103920.

\section{References}

Bhumiratana, N., Adhikari, K., \& Chambers, E. (2014). The development of an emotion lexicon for the coffee drinking experience. Food Research International, 61, 83-92. https://doi.org/10.1016/j.foodres.2014.03.008.

Cardello, A. V., Pineau, B., Paisley, A. G., Roigard, C. M., Chheang, S. L., Guo, L. F., ... Jaeger, S. R. (2016). Cognitive and emotional differentiators for beer: An exploratory study focusing on "uniqueness". Food Quality and Preference, 54, 23-38. https://doi. org/10.1016/j.foodqual.2016.07.001.

Chaya, C., Eaton, C., Hewson, L., Vázquez, R. F., Fernández-Ruiz, V., Smart, K. A., \& Hort, J. (2015). Developing a reduced consumer-led lexicon to measure emotional response to beer. Food Quality and Preference, 45, 100-112. https://doi.org/10.1016/j. foodqual.2015.06.003.

Chollet, S., Valentin, D., \& Abdi, H. (2014). Free sorting task. Novel techniques in sensory characterization and consumer profiling (pp. 207-227). Boca Raton, Florida: CRC Press.

Clore, G. L., Ortony, A., \& Foss, M. A. (1987). The psychological foundations of the affective lexicon. Journal of Personality and Social Psychology, 53(4), 751-766. https:// doi.org/10.1037/0022-3514.53.4.751.

Danner, L., Ristic, R., Johnson, T. E., Meiselman, H. L., Hoek, A. C., Jeffery, D. W., \& Bastian, S. E. P. (2016). Context and wine quality effects on consumers' mood, emotions, liking and willingness to pay for Australian Shiraz wines. Food Research International, 89, 254-265. https://doi.org/10.1016/j.foodres.2016.08.006.

Dorado, Pérez-Hugalde, C., Picard, A., \& Chaya, C. (2016). Influence of first position effect on emotional response. Food Quality and Preference, 49, 189-196. https://doi. org/10.1016/j.foodqual.2015.12.009.

Eaton, C., Chaya, C., Smart, K. A., \& Hort, J. (2019). Comparing a full and reduced version of a consumer-led lexicon to measure emotional response to beer. Journal of Sensory Studies, 34(2), e12481. https://doi.org/10.1111/joss.12481.

Ferrarini, R., Carbognin, C., Casarotti, E. M., Nicolis, E., Nencini, A., \& Meneghini, A. M. (2010). The emotional response to wine consumption. Food Quality and Preference, 21(7), 720-725. https://doi.org/10.1016/j.foodqual.2010.06.004.

Fontaine, J. R., Scherer, K. R., Roesch, E. B., \& Ellsworth, P. C. (2007). The world of emotions is not two-dimensional. Psychological Science, 18(12), 1050-1057. https:// doi.org/10.1111/j.1467-9280.2007.02024.x.

Gmuer, A., Nuessli Guth, J., Runte, M., \& Siegrist, M. (2015). From emotion to language: Application of a systematic, linguistic-based approach to design a food-associated emotion lexicon. Food Quality and Preference, 40, 77-86. https://doi.org/10.1016/j. foodqual.2014.09.001.

Gunaratne, T. M., Gonzalez Viejo, C., Fuentes, S., Torrico, D. D., Gunaratne, N. M., Ashman, H., \& Dunshea, F. R. (2019). Development of emotion lexicons to describe chocolate using the Check-All-That-Apply (CATA) methodology across Asian and Western groups. Food Research International, 115, 526-534. https://doi.org/10.1016/ J.FOODRES.2018.10.001.

Hu, X., \& Lee, J. (2019). Emotions elicited while drinking coffee: A cross-cultural comparison between Korean and Chinese consumers. Food Quality and Preference, 76, 160-168. https://doi.org/10.1016/j.foodqual.2018.08.020.

Josse, J., \& Holmes, S. (2016). Measuring multivariate association and beyond. Statistics 
Surveys, 10, 132-167. https://doi.org/10.1214/16-ss116.

King, S. C., \& Meiselman, H. L. (2010). Development of a method to measure consumer emotions associated with foods. Food Quality and Preference, 21(2), 168-177. https:// doi.org/10.1016/j.foodqual.2009.02.005.

Laros, F. J. M., \& Steenkamp, J.-B. E. M. (2005). Emotions in consumer behavior: A hierarchical approach. Journal of Business Research, 58(10), 1437-1445. https://doi. org/10.1016/j.jbusres.2003.09.013.

Larsen, R. J., \& Diener, E. (1992). Promises and problems with the circumplex model of emotion. Review of Personality and Social Psychology, 13, 25-59.

Lawless, H. T. (1989). Exploration of fragrance categories and ambiguous odors using multidimensional scaling and cluster analysis. Chemical Senses, 14(3), 349-360. https://doi.org/10.1093/chemse/14.3.349.

Manzocco, L., Rumignani, A., \& Lagazio, C. (2013). Emotional response to fruit salads with different visual quality. Food Quality and Preference, 28(1), 17-22. https://doi. org/10.1016/j.foodqual.2012.08.014.

Mora, M., Giussani, B., Pagliarini, E., \& Chaya, C. (2019). Improvement of an emotional lexicon for the evaluation of beers. Food Quality and Preference, 71, 158-162. https:// doi.org/10.1016/j.foodqual.2018.06.007.

Mora, M., Urdaneta, E., \& Chaya, C. (2018). Emotional response to wine: Sensory properties, age and gender as drivers of consumers' preferences. Food Quality and Preference, 66, 19-28. https://doi.org/10.1016/j.foodqual.2017.12.015.

Nestrud, M. A., Meiselman, H. L., King, S. C., Lesher, L. L., \& Cardello, A. V. (2016). Development of EsSense25, a shorter version of the EsSense Profile ${ }^{\circledast}$. Food Quality and Preference, 48(Part A), 107-117. https://doi.org/10.1016/j.foodqual.2015.08.005.

Ng, Chaya, C., \& Hort, J. (2013). Beyond liking: Comparing the measurement of emotional response using EsSense Profile and consumer defined check-all-that-apply methodologies. Food Quality and Preference, 28(1), 193-205. https://doi.org/10. 1016/j.foodqual.2012.08.012.

Parr, W. V., Green, J. A., White, K. G., \& Sherlock, R. R. (2007). The distinctive flavour of New Zealand Sauvignon blanc: Sensory characterisation by wine professionals. Food Quality and Preference, 18(6), 849-861. https://doi.org/10.1016/J.FOODQUAL.2007. 02.001 .

Russel, J. A. (1980). A circumplex model of affect. Journal of Personality and Social Psychology, 39, 1161-1178. https://doi.org/10.1037/h0077714.

Silva, A., Jager, G., van Bommel, R., van Zyl, H., Voss, H.-P., Hogg, T., \& de Graaf, C. (2016). Functional or emotional? How Dutch and Portuguese conceptualise beer, wine and non-alcoholic beer consumption. Food Quality and Preference, 49, 54-65. https://doi.org/10.1016/j.foodqual.2015.11.007.

Silva, A. P., Jager, G., Van Zyl, H., Voss, H., Pintado, M., Hogg, T., \& de Graaf, C. (2016).
Comparing two methods to measure emotions elicited by beer, wine and non-alcoholic beer. Appetite, 101, 236. https://doi.org/10.1016/j.appet.2016.02.133.

Silva, Voss, H.-P., van Zyl, H., Hogg, T., de Graaf, C., Pintado, M., \& Jager, G. (2018) Temporal dominance of sensations, emotions, and temporal liking measured in a bar for two similar wines using a multi-sip approach. Journal of Sensory Studies, 33(5), e12459. https://doi.org/10.1111/joss.12459.

Spinelli, S., Masi, C., Dinnella, C., Zoboli, G. P., \& Monteleone, E. (2014). How does it make you feel? A new approach to measuring emotions in food product experience. Food Quality and Preference, 37, 109-122. https://doi.org/10.1016/j.foodqual.2013. 11.009 .

Thomsen, M., Gourrat, K., Thomas-Danguin, T., \& Guichard, E. (2014). Multivariate approach to reveal relationships between sensory perception of cheeses and aroma profile obtained with different extraction methods. Food Research International, 62 , 561-571. https://doi.org/10.1016/J.FOODRES.2014.03.068.

Thomson, D. M. H., \& Crocker, C. (2013). A data-driven classification of feelings. Food Quality and Preference, 27(2), 137-152. https://doi.org/10.1016/j.foodqual.2012.09. 002.

van Zyl, H. (2016). Emotion in beverages. In H. L. Meiselman (Ed.). Emotion measurement (pp. 473-499). Elsevier. https://doi.org/10.1016/B978-0-08-100508-8.00019-9.

van Zyl, H., \& Meiselman, H. L. (2015). The roles of culture and language in designing emotion lists: Comparing the same language in different English and Spanish speaking countries. Food Quality and Preference, 41, 201-213. https://doi.org/10. 1016/j.foodqual.2014.12.003.

van Zyl, H., \& Meiselman, H. L. (2016). An update on the roles of culture and language in designing emotion lists: English, Spanish and Portuguese. Food Quality and Preference, 51, 72-76. https://doi.org/10.1016/j.foodqual.2016.02.019.

Varela, P., \& Ares, G. (2014). Novel techniques in sensory characterization and consumer profiling. Boca Raton, Florida: CRC Press.

Wakeling, I. N., \& MacFie, H. J. H. (1995). Designing consumer trials balanced for first and higher orders of carry-over effect when only a subset of $k$ samples from t may be tested. Food Quality and Preference, 6(4), 299-308. https://doi.org/10.1016/09503293(95)00032-1.

Watson, D., \& Tellegen, A. (1985). Toward a consensual structure of mood. Psychological Bulletin, 98(2), 219-235. https://doi.org/10.1037/0033-2909.98.2.219.

Yik, M., Russell, J. A., \& Steiger, J. H. (2011). A 12-point circumplex structure of core affect. Emotion, 11(4), 705-731. https://doi.org/10.1037/a0023980.

Addinsoft. (2019). XLSTAT statistical and data analysis solution. Long Island,NY, USA Retrieved from https://www.xlstat.com. 